\title{
Social Determinants of Cardiovascular Diseases
}

\author{
Thierry Lang, $\mathrm{MD}, \mathrm{PhD},{ }^{1}$ \\ Benoit Lepage, MD, ${ }^{1}$ \\ Anne-Cécile Schieber, MD, ${ }^{1}$ \\ Sébastien Lamy, ${ }^{1}$ \\ Michelle Kelly-Irving, $\mathrm{PhD}^{1}$
}

\begin{abstract}
Social determinants of health can be understood as the social conditions in which individuals live and work; conditions that are shaped by the distribution of power, income and resources, as much on a global and national level as on a local level. Social determinants of cardiovascular diseases are found largely outside the healthcare and preventative healthcare systems; but it is important to think in terms of chains of cause and effect, which enable us to see these determinants at work within the system of curative and preventative care, including the management of traditional risk factors. Taking a dynamic perspective on these social determinants of health, and in particular viewing them in a biological and epidemiological context, emphasizes the fact that intervention as early in life as possible is desirable in order to prevent cardiovascular diseases. It is important to act early, before childhood adversities in these critical periods are permanently or irrevocably recorded in the body. In terms of behaviour, focussing health education on adults runs counter to the fact that, with age, it is increasingly difficult to change our behaviour and to overcome biological damage already inflicted. In an area where attention has long been focussed on individual risk factors, underlining the fact that these factors act from infancy allows us to highlight the collective influences on the development of these diseases. Reflecting on health determinants in this way suggests that perhaps the population strategy proposed by Geoffrey Rose may lead to an increase in social inequalities if the modest decrease in risk factors, for example in terms of nutrition, involves the population categories initially most privileged.
\end{abstract}

\footnotetext{
${ }^{1}$ UMR 1027, Inserm-Université Paul Sabatier, Toulouse.

Corresponding Author Contact Information: Thierry Lang at lang@cict.fr; Département d'Epidémiologie et santé publique, UMR Inserm-Université Paul Sabatier 1027, Institut Fédératif d'Etudes et de Recherche Interdisciplinaires Santé Société (IFERISS), Faculté de Médecine, 37, Allées Jules Guesde, 31073 Toulouse, France.
} 
Recommended Citation: Lang T, Lepage B, Schieber AC, Lamy S, Kelly-Irving M. Social determinants of cardiovascular diseases. Public Health Reviews. 2012;33: 601-22.

\section{INTRODUCTION}

The relationship between cardiovascular diseases (CVD) and risk factors such as high blood pressure, cholesterol, smoking, diabetes and physical inactivity has been the subject of extensive study, resulting in an abundance of literature. On the other hand, fewer studies have documented social determinants such as working conditions, housing, or social relationships. In this paper, we suggest that social determinants should not only be juxtaposed with traditional risk factors acting directly on CVD, but also be examined as underlying determinants of some CVDs, and, indeed, as factors acting along causal chains, influencing the incidence and management of traditional risk factors as well as the management of acute coronary events. The goal of this review is not to be exhaustive in discussing all social determinants of CVD, but to emphasise their variety as well as the mechanisms through which they act upon disease, in the light of recent works.

\section{WHY SOCIAL DETERMINANTS HAVE EMERGED AND WHY THEY NEED TO BE EXPLORED}

The broad mechanisms involved in the development of CVDs, including biological and behavioural risk factors, availability of treatments, and an overall fall in CVD rates in industrialised countries, are now well understood. Despite this, there are three issues that highlight the fact that it is essential we improve our knowledge of cardiovascular disease determinants: firstly, social inequalities in health have not disappeared over recent decades, in fact if anything they have increased; secondly, dramatic increases in CVD incidence have been observed after certain rapid social changes, such as in Eastern Europe in the nineties, after the fall of the Soviet Union; and finally, an increase in the incidence of CVD has been observed among some disadvantaged groups. ${ }^{1}$ In France, where, as in many countries of the world, social inequalities in mortality are higher among men than women, a change has been observed in terms of cardiovascular mortality, with higher inequalities emerging among women than among men. ${ }^{2}$ Changes in traditional risk factors do not explain this shift, which may actually be related to societal changes in the role of women at work. 


\section{SOCIAL DETERMINANTS OF HEALTH (SDH)}

Social determinants of health (SDH) can be understood as the social conditions in which individuals live and work; conditions that are shaped by the distribution of power, income and resources, as much on a global and national level as on a local level. The study of these SDH is intended not only to demonstrate the impact of social context on health, but also the mechanisms via which these determinants act on health. This concept first arose in the seventies, when critics suggested that research and public policy should focus more on the societies within which individuals live than on the individuals themselves. It was a move away from a service provided to people when they were ill and towards a public health programme that would help them to stay healthy. SDH condition the physical, social, economic and personal resources an individual has available to them for meeting their needs and aspirations and adapting to their environment.

Although looking at SDH raises the issue of social inequalities in health, it is important to make a distinction between SDH and social determinants "of social inequalities" in health. Certain events and public policies may improve the average state of health of a population whilst at the same time increasing social inequalities in health. There are many examples of this, often related to the introduction of innovative or preventative actions that result in increased inequality.

The purpose of this review is not to discuss the matter exhaustively, but to highlight several characteristics that are easily overlooked when it comes to CVDs, which are quite clearly diseases related not only to the physical and chemical environment but also to the social and economic one. In fact, the vast majority of studies into the link between health and psychosocial factors have been carried out in relation to CVD.

Whilst the question of SDH does not come down simply to social inequalities in health, the latter do demonstrate the shortcomings of a concept of health based on care provided, and on the individual isolated from their social or societal context.

The Ottawa charter for health promotion, which is widely cited, emphasises that the prerequisites for health are peace, shelter, education, food, income, a stable ecosystem and sustainable resources, social justice and equity. This charter is therefore more ambitious than it is usually presented as being, and includes factors that we refer to here as SDH. The best understanding of SDH involves a dynamic concept of their influences throughout life. ${ }^{3}$

In the same way that the idea of following causal chains from birth to adulthood has become progressively obvious, it also applies to cross-sectional 
and synchronic analysis. This method of considering "causes" is fundamental in the domain of SDH. According to Helman, "the idea of cause has become meaningless other than as a convenient designation for the point in the chain of event sequences at which intervention is most practical". ${ }^{4}$ We have to bear in mind that every risk factor is a link in a chain that we can sometimes, but not always, piece together from end to end. The biological "downstream" effects of risk factors are accepted and integrated. But the notion that there is an "upstream" cause in this causal chain is examined much less often. For example, the various SDH are not limited to the personality of an adolescent who starts to smoke, but integrate that adolescent's behaviour within a wider social, economic and societal context. These causal chains may link back to what we consider "fundamental" causes, which we find at the origin of many diseases or behaviours. These fundamental causes include factors such as social environment during infancy, level of education, income, economic and social policies, and education policies.

A scientific debate separates those who believe that psychosocial mechanisms are key, who accord importance to perceptions and social relationships, and those who insist on the importance of "objective", material conditions. ${ }^{5,6}$ The materialist hypothesis accords a predominant role to material conditions and their consequences on health. The approach concentrates on access to water, food, and chemical and physical exposure. Under this hypothesis, the "health behaviour" of an individual is considered more to be the product of social structures than a matter of individual responsibility. On the other hand, the psychosocial explanation postulates that material conditions have less influence on health than the psychological "stress" associated with the perception of a socioeconomic disadvantage (in developed societies, at any rate). According to Wilkinson, for example, cited in Leclerc, income does not necessary enable access to physical and material goods, but does indicate social status. ${ }^{7}$ The vast majority of work looking at the link between health and psychosocial factors has been carried out in the domains of CVD and mental health.

However, the two approaches, psychosocial and materialist, are not conflicting ones. In 2007, working conditions for employees and labourers in France were characterised by physically strenuous work and exposure to harmful physical and chemical factors, all of which are considered material factors. At the same time, studies on workplace organisation have demonstrated the importance of psychosocial explanations (e.g., such as the effort-reward imbalance model), which should not be considered as individual factors: we must understand how a workplace structure, which can be adjusted, translates into individual experience. 


\section{SOCIAL DETERMINANTS: WHAT ARE THE KEY FACTORS?}

The relationship between social determinants and CVD has been observed in many studies. ${ }^{8}$ We will focus on some main categories of social determinants of CVD: professional context (working conditions and access to a job), social relationships and isolation, geographic environment and "ethnicity". Social determinants have been shown to be related to various CVDs in various ways. Indeed, from an epidemiological point of view, psychological stress has been linked to the development of cardiovascular risk factors such as hypertension and atherosclerosis. Self-perceived stress, as well as stress-related measures such as sense of coherence, have also been associated with stroke. ${ }^{9,10}$

\section{WORK}

In 2004, a large international case-control study (Interheart) was carried out in 52 countries on nearly 25,000 people. It estimated that "permanent stress" doubled the risk of myocardial infarction. These results were added to the numerous studies that, for over a decade, have indicated that exposure to chronic stress is a predictor of cardiovascular mortality and morbidity. Adverse psychosocial conditions, including work stress, were associated with a mean 2.7 increased risk of myocardial infarction and contributed to 35 percent of the population attributable risk. ${ }^{11}$

It is important to note that the term "stress" is inappropriate and ambiguous. Stress is a psychological reaction to a stressing agent, either acute or chronic. In the case of "work-related stress", our knowledge has increased since epidemiologists have been able to define certain types of workplace organisational structure liable to generate chronic stress, and, from these situations, to construct validated measurement instruments. Two principal models, from validated questionnaires, allow us to quantify exposure to these pressures. The first of these, Karasek's questionnaire, starts from the hypothesis that a high job-strain situation is characterised by a large workload combined with a low-level of employee control in deciding how to carry out this work, organise their time and use their skills. The employee is subject to an imposed rhythm and does not make decisions about their work. The other model used (Siegrist), ${ }^{12}$ postulates that a job is characterised by effort, work intensity and personal investment, on the one hand, and professional, social and financial recognition on the other. These two models are independent and may be combined. They show, with great coherence, the impact that stress related to the working environment has on cardiovascular health, increasing risk by two to three times. ${ }^{7}$ 
A recent study presents additional arguments in favour of the causality of this relationship and suggests that several mechanisms are involved. ${ }^{13}$ In this study, unfavourable working conditions were measured using the "job strain questionnaire" (Karasek's questionnaire). The results of this analysis of the Whitehall II study confirm this association and note, for the first time, a dose-effect relationship between exposure to job strain and the onset of coronary heart disease: the longer the period of exposure, the higher the incidence $(+40 \%$ for one period of exposure, $+68 \%$ for two periods). This relationship is most evident in middle-aged employees, a fact which may be linked to the effects of workers in bad health leaving work. These results were adjusted for age, sex, employment grade, hypertension, total cholesterol and smoking. The prospective nature of the study, the coherence with other studies and the dose-effect relationship are strong arguments in favour of causality.

The other outcome of this study was an understanding of the mechanisms at work: behavioural changes, metabolic syndrome and the role of cortisol and the sympathetic nervous system. Health behaviours (e.g., low-levels of physical activity and poor eating habits) and metabolic syndrome explain around 32 percent of the effect of job stress on the incidence of coronary heart disease. The relative risk of metabolic syndrome is 1.33 for one exposure period to job stress and 1.72 for a double exposure period, indicating a dose-effect relationship. In the last cross-sectional analysis, therefore without causality, an association was found between job strain and a morning rise in cortisol levels. The link between job stress and heartrate variability suggests that stress at work leads to sympathetic mechanisms and electrical instability of the heart. This study reminds us of the need to define the elements of workplace organisation that put an individual in a situation in which they may develop "chronic stress" and reinforces the causal link with new arguments, in particular the dose-effect relationship. Lastly, it notes that there are multiple mechanisms at work, acting directly at a biological level or indirectly via health behaviour. Work is clearly a factor, but the extent of the part it plays in all types of coronary heart disease (CHD) is still to be determined.

Other studies looking at healthcare professions illustrate the influence of the working environment on the health of these professionals. In the hospital sector, psychosocial constraints at the workplace have increased during the last two decades due to changes in workplace organization. ${ }^{14}$ These psychosocial constraints have been shown to be linked to cardiovascular diseases. ${ }^{12,15}$ In a study of 3,837 hospital workers (ORSOSA), higher systolic blood pressure and to a lesser degree diastolic blood pressure, were found to be associated with poor relationships within the 
team, in nurses as well as in nursing assistants. ${ }^{16}$ This is consistent with reports showing that conflict may lead to a higher incidence of coronary heart diseases. ${ }^{17}$ It is also in keeping with a study showing that difficulties and conflict with a supervisor may be related to high blood pressure. ${ }^{16}$ Negative social interactions were found to be related to higher blood pressure levels, whereas, among men, at any rate, having supportive co-workers had the inverse effect. ${ }^{18}$

\section{UNEMPLOYMENT AND JOB INSTABILITY}

The high mortality rate of the unemployed compared with those engaging in a professional activity is only partially explained by selection effects. An unstable situation, whether it involves unemployment or the fear of losing a job, has various effects on cardiovascular health. These effects may also impact those in other types of unstable employment, such as fixed-term contracts, involuntary part-time work, seasonal work and internships. Restructuring operations have consequences not only on the individuals who find themselves unemployed, but also on the "survivors". Between 1993 and 2000, during a period of rapid growth in unemployment in Finland, cardiovascular mortality within companies in four towns increased by 50 percent where staff reductions of eight to 18 percent were made, and by 100 percent where the reduction was over 18 percent, compared with companies where no staff cuts were made. Selection effects linked to health were excluded. ${ }^{19}$

So why are work-related risk factors so poorly acknowledged? CVD may occur a long time after exposure has ceased; multiple factors may be involved and the link is only a probable one. Many employees who suffer a myocardial infarction will have other risk factors (such as smoking and high cholesterol), and it can then be tempting to focus on those individual risk factors, overlooking the effect of work. In the long term, the strategy for preventing CVD should not only be designed to be applied "within" the family and professional environment, but "upon" this environment, on the individual and their reactions. "Stress management" courses should be offered to employees. This is really an issue of the interaction between an employee and their environment. ${ }^{?}$ 


\section{SOCIAL ISOLATION}

Social isolation considerably increases the risk of death due to myocardial infarction. Increased overall and cardiovascular mortality rates have been observed where no social support network exists, more consistently in men than in women. ${ }^{7}$ This data on the effect of social relationships on overall and cardiovascular mortality rates has been confirmed by a recent metaanalysis. The association is more or less marked according to the social relationship measurement. The odds-ratio is higher for complex measurements of social integration than for binary measurements (living alone versus other arrangements). ${ }^{20}$ Multiple mechanisms are suggested, involving instrumental support (money and other help), emotional support, encouragement to access medical and preventative care, and a direct neurohormonal effect. Social networks, depending on the number of social contacts, friends, family members, work colleagues or neighbours an individual has and the social support that they can provide, have both a material and psychosocial impact, since their support may involve not only communication and emotional support, but also material or financial assistance.

\section{GEOGRAPHICAL LOCATION}

Links between CVD, mortality or hospitalisations, and short and long term fluctuation in atmospheric pollution relate not only to particulate matter, but also to ozone, carbon monoxide, nitrogen dioxide and sulphur dioxide. ${ }^{21}$ However, the distribution of populations with regard to pollution is not random. Due to property prices, populations of a low socioeconomic status (SES) are more exposed to pollution. ${ }^{22}$ A Canadian cohort study confirms that exposure to environmental pollutants and traffic pollution explains, at least in part, the social gradient in health that has been observed. ${ }^{23}$ Cardiovascular risks, in particular an increased risk of myocardial infarction in the short term associated with low temperatures, have been welldocumented. ${ }^{24}$ Being able to heat the home, the quality of the insulation and therefore the temperature inside the home seem to play a major role. A British study suggests that green spaces also have a beneficial effect. The inequality gradient was reduced by the presence of green spaces, even after stratification based on the area's level of deprivation..$^{25}$ 


\section{DISCRIMINATION AND ETHNICITY}

In France, questions of ethnicity in national statistics spark lively debate. It is worth defining ethnicity as a complex and changing social phenomenon that involves imposed categories as well as self-assigned identity. The majority of immigrants and their descendants belong to disadvantaged social categories. The issue is whether various types of discrimination, related to skin-colour, place of birth or surname, may have a detrimental effect on health beyond that of their social group (e.g., education and profession) and material quality of life. Epidemiological indicators must specify the different types of discrimination encountered, and distinguish discrimination perceived individually versus that perceived by the group, and the fear of discrimination versus actual discrimination.

Such data do exist in Britain. The 1999 Health Survey for England found that "the highest prevalence of [Ischaemic heart disease or stroke] among men's age groups was found among Indian men aged 55 and over". ${ }^{26}$ Hypertension amongst ethnic minority groups was, on the whole, lower than for the majority population, except for Caribbean respondents who showed an age standardised relative risk of 1.79 for women, and 1.47 for both men and women. ${ }^{27}$ However, a social-class gradient is seen in most of the health and disease examples cited above. Using various indicators of SES, "those in poorer socio-economic groups had poorer health in each ethnic group" in terms of heart disease, hypertension, diabetes, respiratory illnesses and health behaviours. SES is thus an important predictor of health within ethnic groups. ${ }^{25}$

A United States review of published works shows a link between hypertension and institutional racism. ${ }^{28}$ It would be helpful to undertake similar studies on discrimination in more European countries.

\section{TRADITIONAL RISK FACTORS}

The extent to which socioeconomic inequalities in health are explained by traditional risk factors, in particular smoking and obesity, varies considerably between studies and countries. In the Whitehall II cohort, for example, the proportion of the association is 75 percent, but it is only 19 percent in the GAZEL cohort, using comparable methods..$^{29}$ In this study, the association described between low SES and health behaviours relates to smoking, heavy alcohol consumption, an unhealthy diet and physical inactivity. Certain authors have underlined the fact that if traditional risk factors did not account for the entire social gradient of cardiovascular 
mortality, prevention strategies against these traditional factors implemented in the disadvantaged groups would not reduce inequalities. This does not take into account the social distribution of these risk factors and the causes that explain their high prevalence and low-levels of care, two observations linked to social determinants. The social stratification of these behaviours and their grounding in societies and cultures has been presented in many studies. ${ }^{7,30}$ Analysis of "individual" behaviour therefore reflects not only a social environment but also a personal and collective history.

Understanding lay perceptions of these diseases and their risk factors is an important step in determining the optimal effectiveness of a public health campaign. Knowledge of risk factors is also likely to influence a patient's initial contact and compliance with primary care. Studies have shown differing levels of awareness or knowledge of the main risk factors in populations worldwide (hypertension, smoking and diet), as well as citing non-established risk factors. It is worth debating whether campaigns to increase public awareness and information passed on by practitioners should be based purely on biomedical evidence, and to what extent messages need to be adapted to specific socio-cultural settings. ${ }^{31}$

\section{HEALTHCARE SYSTEM}

It may seem strange to include healthcare systems as SDH, especially since their central role among SDH has been readily challenged in epidemiological literature. Two key points deserve to be mentioned here that underline the benefit of this approach. Even though the role of the healthcare system is not a central one in terms of mortality, this is probably not the case in other aspects of health, such as quality of life, dependency, or even perceived health. Above all, by considering the healthcare system as an SDH we emphasize the system's role as an intermediary between health and the most fundamental causes of disease. It has been suggested that inequalities within the health system should be categorised either as inequalities by construction, meaning that the organisation of the system creates inequalities, or by "omission" meaning that the problem is overlooked. ${ }^{32}$

\section{Inequalities by Construction}

It has been shown, to some extent, that access to healthcare explains the link between SES and CHD. ${ }^{32,33}$ Clinical decision rules that rely on risk assessment using traditional cardiovascular risk models may be an example of how differences in access to healthcare could exacerbate social inequalities. ${ }^{34}$ Some guidelines suggest that the decision to start drug 
therapy for mild hypertension or mild hypercholesterolemia should be based on the total cardiovascular risk estimated using the SCORE risk model or the Framingham risk model, rather than on blood pressure or cholesterol levels alone. ${ }^{35}$ These models use individual biological or medical risk factors (e.g., age, blood pressure, cholesterol levels, diabetes and smoking habits) and do not take into account psychosocial factors ${ }^{36,37}$.

Thus, ignoring patients' psychosocial status when scoring total cardiovascular risk using traditional models could lead to the underestimation of the true cardiovascular risk for patients of low SES or depressed individuals. Where the treatment strategy relies on a total cardiovascular risk value estimated on biomedical factors, this underestimation could then result in a delay in the provision of drug therapy to these patients. ${ }^{34}$

It has been shown that calibration of the Framingham function depended on SES. ${ }^{38,39}$ Results from a cohort study of 6,185 men showed that whilst cardiovascular clinical decision rules relying on overall cardiovascular risk assessment improved cardiovascular health, the use of biomedical risk functions without consideration of psychosocial status could increase health inequalities in depressive subjects and subjects with low educational attainment. In both cases, treatment would be delayed by more than four years. ${ }^{38} \mathrm{New}$ cardiovascular risk models including area-based measures of social deprivation and ethnicity were recently derived from populations in Scotland and the United Kingdom (ASSIGN and QRISK scores). These functions successfully adjust for the effect of SES or ethnicity but are only applicable to UK residents. . $^{41,42}$

\section{Inequalities by Omission}

In this situation, the mechanisms involved are not related to institutional processes or decision rules. Failures result from the fact that social determinants are not included in daily care procedures. As a result, a social gradient has been observed in relation to blood pressure levels under treatment. ${ }^{43}$ Similarly, glycaemic control and the prescription of a funduscopy have been observed to be more frequent among patients with a higher level of education. ${ }^{30}$

\section{The role of the Ambulatory System}

Hospital care in France was found to be provided equally to patients with an acute coronary event, regardless of their educational level, whereas ambulatory care and follow-up were not; the higher the patient's educational level, the more treatments and investigations were recorded before the acute coronary event. ${ }^{44}$ 
The interaction between patients and their general practitioner (GP) is a key element in the efficiency and usage of health services. It varies depending on patient characteristics. ${ }^{45}$ If, as the evidence suggests, the patient-physician relationship affects patients' healthcare trajectory (i.e., how they are treated and their compliance with treatments) this could lead to health inequalities that will permeate across the healthcare system.

Understanding interactions between patients and GPs is thus potentially important for optimising communication during consultations and improving health promotion, notably in the management of cardiovascular risk factors ${ }^{34}$ and facets of the patient-physician interaction that may generate health disparities, notably concerning the management of cardiovascular risk factors in the context of primary care. Patients' age played a significant role in the concordance between physicians and patients, and was closely related to the level of education, with older patients having the lowest level of education. ${ }^{46}$ It is likely, therefore, that both age and level of education play a role in determining concordance between patients and GPs, whereby mutual comprehension may be affected when the patient is older and/or has a low education level.

This could potentially lead to misunderstandings between patients and GPs and, consequently, to the quality of care being compromised. Doctors perceived that they listened, examined, and gave advice less often to patients in the lowest social class compared to those in the upper social classes, and gave explanations more often to males than females. Physicians were more likely to discuss diet and exercise with high-income patients than those from a low-income group; however, they were more likely to discuss smoking with low-income patients. ${ }^{47,48}$

A rich international literature highlights that a patient's inclination to participate in medical decision making, notably on CVD management, varies by characteristics such as age and education, but also by sex, coping style, and severity of condition. ${ }^{45,49}$ Taking age and educational level into account during a consultation in general practice could improve mutual comprehension between physicians and their patients, and therefore the quality of care, particularly in relation to management of cardiovascular risk factors. Future research on how best to advise patients on nutrition and exercise could be a first step. An analysis reveals that, where patients had a low-level of education, GPs tended to evaluate patients' health more positively relative to the individual's own evaluation. Even if neither of the two assessments of health can be defined as "correct", the widening gap between the evaluations, along with the patient's lower educational level suggests that GPs potentially overestimate the health of patients with a lower level of education. 
If people with a low-level of education who consider themselves in poor health are not identified as such in the primary care system, this could potentially result in lack of advice and treatment for these patients and ultimately the persistence of health inequalities. The issue of social distance between GPs and patients and its effects on communication may be an important point to be addressed when training junior doctors, especially in general medicine where they are likely to be gatekeepers to secondary healthcare.

\section{RISK FACTORS OVER TIME: THE EFFECTS OF ACCUMULATIVE AND SEQUENTIAL RISK FACTORS}

There is quite a broad consensus on the fact that what happens in the womb and during early life is crucial: persistent socioeconomic disadvantages during childhood and adolescence have been show to predict future ill health, cumulatively resulting in impairments. ${ }^{50}$ This accumulative effect is both cross-sectional, because certain individuals may be exposed to several risk factors at a given point (related to work, home and geographical environment, for example), and longitudinal, from early infancy to adulthood. An early disadvantage in life may set an individual on a risk pathway leading to future exposure which represents the important etiological event. ${ }^{51}$ These chains of causality may link back to causes classed as "fundamental", which we find at the origin of many diseases (such as income, level of education, economic and social policy, education policy, etc.)

\section{DEVELOPMENTAL ORIGINS OF CVD}

In the 1970s, Anders Forsdahl showed associations between infant mortality and subsequent adult mortality from arteriosclerotic disease in Norway. Forsdahl's conclusions from his analyses state that: "the correlation between living conditions and later mortality from arteriosclerotic disease is so marked that it seems justified to consider a poor standard of living in early years followed by prosperity as a potential risk factor". ${ }^{50}$

Forsdahl's findings and the concept of critical periods in early growth are reflected in the work of Barker et al. on historical birth cohorts in the UK. The authors hypothesise that "adverse influences in childhood associated with poor living standards increase susceptibility to other influences, associated with affluence, encountered in later life". ${ }^{53}$ Barker et al. proposed hypothesis and the subsequent studies carried out were 
landmark events in the epidemiological understanding of chronic diseases responsible for the main burden of disease in rich countries. Their suggestions offered an understanding of why genetic and adult risk factors did not provide sufficient explanation for CVDs. Studies looking at historical data from hospitals, as well as prospective cohort studies and natural experiments such as the Dutch famine, provided Barker et al. with evidence of associations between poor foetal nutrition and CVD, noninsulin dependent diabetes, hypertension, insulin resistance and raised cholesterol levels. ${ }^{54}$ Hardy et al. found that men with the lowest birthweight had consistently higher mean systolic blood pressure, and that, in both men and women, those from manual social class backgrounds tended to have higher blood pressure. ${ }^{55}$ Roberts et al. have shown that early-life socioeconomic situation (measured by parental education, occupation and home ownership) was associated with an increased risk of heart failure (HR $=$ $1.39,95 \% \mathrm{CI}=1.00-1.95$ in a black population, and $\mathrm{HR}=1.32,95 \% \mathrm{CI}=$ 1.06-1.64, in a white population). ${ }^{56}$

In one of their studies of the Dutch famine cohort, Roseboom conducted analyses on individuals born in Amsterdam, whose data was obtained from clinical exams and interviews in adulthood. The results show associations between famine exposure in early gestation and prevalence of CHD independently of confounding factors ${ }^{57}$ After the abrupt end to the famine in the Netherlands, mothers who were exposed early in pregnancy were subsequently well nourished and went on to have above average sized babies. The results show that these babies tended to have a higher prevalence of CHD in adulthood. The authors thus conclude that "the transition from nutritional deprivation in early gestation to nutritional adequacy later on has led to metabolic conflicts, which in turn resulted in an increased risk of coronary heart disease". Wamala et al. conducted a case-control study of 292 women under the age of 66 with CHD and 292 controls matched by age and area. ${ }^{58}$ The results show that both early and later exposures to socioeconomic disadvantage are associated with increased CHD risk. Later life socioeconomic disadvantage was more harmful to the women's cardiovascular health than exposure in early life. ${ }^{58}$ The cumulative measure of lifetime socioeconomic disadvantage showed a graded increase in the risk of CHD with increasing lifetime disadvantage.

Early life exposure to Adverse Childhood Experiences (ACE), like trauma, abuse or maltreatment in childhood, has been linked to alteration of the brain structure and the neurobiological stress-response systems, which in turn have consequences for health and emotional well-being. ${ }^{59}$ Studies have described associations between ACE and health outcomes such as 
ischaemic heart disease,${ }^{60}$ obesity, ${ }^{61,62}$ perceived health as well as premature mortality. In many studies, a dose-response association was observed, where an increasing number of accumulated adversities was associated with a higher risk of morbidity. These diverse points of view give very different perspectives on the causes of disease. In 2002, the greatest contributors to the disease burden in the WHO European Region were, in order of size of impact: smoking, hypertension, alcohol abuse, high cholesterol, obesity, insufficient intake of fruit and vegetables, and lack of physical exercise. But examining these fundamental causes more closely highlights neoliberal trade policies, income inequalities, poverty, workrelated risk-factors and a lack of social cohesion. ${ }^{63}$

\section{LIVING IN A GEOGRAPHICAL ENVIRONMENT}

The British epidemiologist Geoffrey Rose introduced a double level of reflection between individuals and populations. For him, the role of epidemiology consists not only of knowing the factors that explain why a certain individual is "sick", but also the factors that explain why a certain population is "sick". ${ }^{64}$

The study of the role of the physical and social environment, independently of the social characteristics of the individual themselves, has been stimulated by the use of multilevel models. The mechanisms by which this neighbourhood effect works are probably competitive, and variable according to the disease. Obvious direct mechanisms are those which involve the physical characteristics of the residential area and health (e.g., air pollution or road traffic noise). The physical environment may also facilitate certain health behaviours, for example the availability and price of various foods, and the ability to take physical exercise in the residential area.

The social characteristics of a neighbourhood, such as social cohesion or disruption, may play a role, but there are still only a small number of studies on these influences. A "contagion" effect is a theoretical possibility but has not yet been studied. This effect does not relate to infectious diseases, but to behaviours considered "individual", such as smoking. Lastly, the environment may be a place of social interaction that shapes people's values, expectations and habits.

Overall, recent multilevel studies have confirmed that compositional and contextual effects are major SDH. Although, in most of the studies, the same administrative boundaries were used for feasibility reasons, the relevant geographical level is not the same for different health issues and 
potential mechanisms. In a systematic review of 131 articles published since 2006, only four longitudinal studies were found. The environmental characteristics found to relate in a coherent way to either obesity or hypertension include geographical zones of low SES and low-levels of urban planning, with low density of road intersections, availability of services and residential population density. A high-level of noise pollution, little access to supermarkets and a high density of local convenience stores were identified, as well as low social cohesion.

According to this review, there has been very little investigation into the mechanisms which link environmental characteristics to levels of cardiovascular risk factors. ${ }^{65}$ Several environmental studies have been conducted in the Paris region. They show a high level of hypertension in zones with a low average level of education, after individual adjustment. A high body mass index and waist circumference explain around half of this association between neighbourhood educational level and hypertension. ${ }^{66}$ After adjustment for individual variables, body mass index and waist circumference increased with a decreasing density of services available in terms of physical activity and healthy food (fruits and vegetables). The precise mechanisms of the associations observed in these studies are still to be determined, especially since the various characteristics are all heavily intercorrelated. The services offered and the ability to walk, both for practical purposes and for leisure purposes in green spaces, are particularly closely correlated. Preliminary studies suggest also links between obesity and supermarkets visited. ${ }^{67}$

\section{INTERACTION OF GENETICS, BIOLOGY AND SOCIAL ENVIRONMENT}

A 30-year study conducted on 144 nuns and 138 controls living around a monastery in Italy ${ }^{68}$ illustrates the societal effect and its interaction with the environment. For the nuns, almost their entire lives were spent in complete isolation and near-silence. Although urinary salt excretion in the two groups of individuals remained similar throughout the study, blood pressure in the control group increased with age, whilst that of the nuns remained constant. After 30 years, the difference in blood pressure was $30 / 15 \mathrm{mmHg}$. The effect of a high salt intake is therefore reduced by a life in this distinctive environment, which features lack of stress, silence and isolation from society. There are concrete arguments to suppose that the social environment alters gene expression, ${ }^{69}$ however this approach does not resolve the great problem of social epidemiology, that of characterising social environment. 


\section{CONCLUSION}

There are many social determinants of CVD. They are found largely outside the healthcare and preventative healthcare systems; but it is important to think in terms of chains of cause and effect, which enable us to see these determinants at work within the system of curative and preventative care, including in the management of traditional risk factors.

Taking a dynamic perspective on these SDH, and in particular viewing them in a biological and epidemiological context, we can see that intervention as early in life as possible is desirable in order to prevent CVD. It is important to act early, before childhood adversities in these critical periods are permanently or irrevocably recorded in the body. In terms of behaviour, focussing health education on adults runs counter to the fact that, with age, it is increasingly difficult to change our behaviour and to overcome biological damage already inflicted. ${ }^{59} \mathrm{In}$ an area where attention has long been focussed on individual risk factors, underlining the fact that these factors act from infancy allows us to highlight the collective influences on the development of these diseases. We must remember that atherosclerotic lesions were noted in American soldiers as young as 20 years old in the Korean War.

Reflecting on health determinants in this way suggests that perhaps we should extend Geoffrey Rose's strategy ${ }^{64}$ Rose, a British epidemiologist, proposed a high-risk strategy to prevention, targeted at individuals with a high-level of cardiovascular risk factor, and the population strategy, which consisted of shifting the distribution curve of these risk factors by several $\mathrm{mmHg}$ of blood pressure or millimoles of cholesterol, bringing minimal benefit to the individual but an appreciable gain to the population in terms of mortality.

In the light of recent works on the consequences of prevention campaigns, this population strategy may lead to an increase in social inequalities if the modest decrease in risk factors, for example in terms of nutrition, involves the population categories initially most privileged. This is why several authors have suggested extending Rose's approach using the notion of vulnerable populations, aiming to prevent damaging effects by taking into account $\mathrm{SDH} .{ }^{70}$

\section{Acronyms list:}

$\mathrm{ACE}=$ Adverse Childhood Experiences

$\mathrm{CHD}=$ Coronary Heart Disease

$\mathrm{CVD}=$ Cardiovascular Disease

GP $=$ General Practitioner

$\mathrm{SDH}=$ Social Determinants of Health

SES $=$ Socioeconomic Status 


\section{REFERENCES}

1. O'Flaherty M, Bishop J, Redpath A, McLaughlin T, Murphy D, Chalmers J, et al. Coronary heart disease mortality among young adults in Scotland in relation to social inequalities: time trend study. BMJ. 2009;339:b2613.

2. Saurel-Cubizolles MJ, Chastang JF, Menvielle G, Leclerc A, Luce D; EDISC group. Social inequalities in mortality by cause among men and women in France. J Epidemiol Community Health. 2009;63:197-202.

3. Kreatsoulas C, Anand SS. The impact of social determinants on cardiovascular disease. Can J Cardiol. 2010;26:8C-13C.

4. Helman, in Blakely AB, Woodward AJ. Ecological effects in multi-level studies. J Epidemiol Community Health. 2000;54:367-74.

5. Lynch JW, Smith GD, Kaplan GA, House JS. Income inequality and mortality: importance to health of individual income, psychosocial environment, or material conditions. BMJ. 2000;320:1200-4.

6. Marmot M, Wilkinson RG. Psychosocial and material pathways in the relation between income and health: a response to Lynch et al. BMJ. 2001;322:1233-6.

7. Leclerc A, Kaminski M, Lang T. Inégaux face à la santé: du constat à l'action. Paris: La Découverte Ed. 2008. p.298.

8. Huisman M, Kunst AE, Bopp M, Borgan JK, Borrell C, Costa G, et al. Educational inequalities in cause-specific mortality in middle-aged and older men and women in eight western European populations. Lancet. 2005;365:493-500.

9. Jood K, Redfors P, Rosengren A, Blomstrand C, Jern C. Self-perceived psychological stress and ischemic stroke: a case-control study. BMC Med. 2009;7:8.

10. Surtees PG, Wainwright NWJ, Luben RL, Wareham NJ, Bingham SA, Khaw KT. Adaptation to social adversity is associated with stroke incidence evidence from the EPIC-Norfolk prospective cohort study. Stroke. 2007;38:1447-53.

11. Rosengren A, Hawken S, Ounpuu S, Sliwa K, Zubaid M, Almahmeed WA, et al.; INTERHEART investigators. Association of psychosocial risk factors with risk of acute myocardial infarction in 11,119 cases and 13,648 controls from 52 countries (the INTERHEART study): case-control study. Lancet. 2004; 364:953-62.

12. Bosma H, Peter R, Siegrist J, Marmot M. Two alternative job stress models and the risk of coronary heart disease. Am J Public Health. 1998;88:68-74.

13. Chandola $\mathrm{T}$ et al. Work stress and coronary heart disease: what are the mechanisms? Eur Heart J. 2008;29:640-8.

14. Bourbonnais R, Brisson C, Malenfant R, Vézina M. Health care restructuring, work environment, and health of nurses. Am J Ind Med. 2005;47:54-64.

15. Kivimäki M, Leino-Arjas P, Luukkonen R, Riihimäki H, Vahtera J, Kirjonen J, Work stress and risk of cardiovascular mortality: prospective cohort study of industrial employees. BMJ. 2002;325:857. 
16. De Gaudemaris R, Levant A, Ehlinger V, Hérin F, Lepage B, Soulat JM, et al. Blood pressure and working conditions in hospital nurses and nursing assistants. The ORSOSA study. Arch Cardiovasc Dis. 2011;104:97-103.

17. Lipovetzky N, Hod H, Roth A, Kishon Y, Sclarovsky S, Green MS. Emotional events and anger at the workplace as triggers for a first event of the acute coronary syndrome: a case-crossover study. Isr Med Assoc J. 2007;9:310-315.

18. Pickering TG. Reflections in hypertension: work and blood pressure. J Clin Hypertens (Greenwich). 2004;6:403-405.

19. Vahtera J, Kivimaki M, Pentti J, Linna A, Virtanen M, Virtanen P, et al. Organisational downsizing, sickness absence, and mortality: 10-town prospective cohort study. BMJ. 2004;328:555-60.

20. Holt-Lunstadt J, Smith TB, Layton JB. Social relationships and mortality risk: a meta-analytic review. PLoS Med. 2010;7:1-20.

21. Bhaskaran K, Hajat S, Haines A, Herrett E, Wilkinson P, Smeeth L. Effects of air pollution on the incidence of myocardial infarction. Heart. 2009;95:1746-59.

22. Deguen S, Zmirou-Navier D. Social inequalities resulting from health risks related to ambient air quality - a European review. Eur J Public Health. 2010;20:27-35.

23. Finkelstein MM., Jerrett M., Sears MR. Environmental inequality and circulatory disease mortality gradients. J. Epidemiol. Community Health. 2005;59:481-7.

24. Bhaskaran K, Hajat S, Haines A, Herrett E, Wilkinson P, Smeeth L. Effects of ambient temperature on the incidence of myocardial infarction. Heart. 2009;95:1760-9.

25. Mitchell R, Popham F. Effect of exposure to natural environment on health inequalities: an observational population study. Lancet. 2008;372:1655-60.

26. Primatesta P, Brookes M. Cardiovascular disease: prevalence and risk factors. In: B Erens, P Primatesta and G Prior, editors. Health survey for England: the health of minority ethnic groups. London: The Stationery Office; 2001.

27. Nazroo J, Davey Smith G. The contribution of socio-economic position to health differentials between ethnic groups: evidence from the United States and Britain. In: Health and Ethnicity. Macbeth H, Shetty P, editors. London: Taylor and Francis; 2001.

28. Brondolo E, Love EE, Pencille M, Schoenthaler A, Ogedegbe G. Racism and hypertension: a review of the empirical evidence and implications for clinical practice. Am J Hypertens. 2011;24:518-29.

29. Stringhini S, Dugravot A, Shipley M, Goldberg M, Zins M, Kivimäki M, et al. Health behaviours, socioeconomic status, and mortality: further analyses of the British Whitehall II and the French GAZEL prospective cohorts. PLoS Med. 2011;8:e1000419.

30. Beauchamp A, Peeters A, Wolfe R, Turrell G, Harriss LR, Giles GG, et al. Inequalities in cardiovascular disease mortality: the role of behavioural, physiological and social risk factors. J Epidemiol Community Health. 2010;64:542-8. 
31. Kelly-Irving M, Mulot S, Inamo J, Ruidavets JB, Atallah A, Lang T. Improving stroke prevention in the French West Indies: limits to lay knowledge of risk factors. Stroke. 2010;41:2637-44.

32. Lombrail P, Pascal J, Lang T. Accès au système de soins et inégalités sociales de santé : que sait-on de l'accès secondaire ? Santé, Société et Solidarité. Revue de l'observatoire Franco-québecois de la Santé et de la Solidarité. 2004;No2:61-71.

33. Steptoe A, Marmot M. The role of psychobiological pathways in socio-economic inequalities in cardiovascular disease risk. Eur Heart. 2002;23:13-25.

34. Lang T. Ignoring social factors in clinical decision rules: a contribution to health inequalities? Eur J Public Health. 2005;15:441.

35. Graham I, Atar D, Borch-Johnsen K, Boysen G, Burell G, Cifkova R, et al. European guidelines on cardiovascular disease prevention in clinical practice: executive summary. Atherosclerosis. 2007;194:1-45.

36. Conroy RM, Pyorala K, Fitzgerald AP, Sans S, Menotti A, De Backer G, et al. Estimation of ten-year risk of fatal cardiovascular disease in Europe: the SCORE project. Eur Heart J. 2003;24:987-1003.

37. Kannel WB, D'Agostino RB, Sullivan L, Wilson PW. Concept and usefulness of cardiovascular risk profiles. Am Heart J. 2004;148:16-26.

38. Brindle P, Beswick A, Fahey T, Ebrahim S. Accuracy and impact of risk assessment in the primary prevention of cardiovascular disease: a systematic review. Heart. 2006;92:1752-9.

39. Tunstall-Pedoe H, Woodward M. By neglecting deprivation, cardiovascular risk scoring will exacerbate social gradients in disease. Heart. 2006;92:307-10.

40. Lepage B, Amouyel P, Arveiler D, Ferrières J, Ducimetière P, Lang T. Could clinical decision rules relying on cardiovascular risk models increase psychosocial inequalities in health? Results from the PRIME cohort study. Prev Med. 2011;52:439-44.

41. Hippisley-Cox J, Coupland C, Vinogradova Y, Robson J, May M, Brindle P. Derivation and validation of QRISK, a new cardiovascular disease risk score for the United Kingdom: prospective open cohort study. BMJ. 2007;335:136.

42. Hippisley-Cox J, Coupland C, Vinogradova Y, Robson J, Minhas R, Sheikh A, et al. Predicting cardiovascular risk in England and Wales: prospective derivation and validation of QRISK2. BMJ. 2008;336:1475-82.

43. de Gaudemaris R, Lang T, Chatellier G, Larabi L, Lauwers-Cances V, Maitre A, et al. Socioeconomic inequalities in hypertension prevalence and care: the IHPAF Study. Hypertension. 2002;39:1119-25.

44. Lang T, Ducimetière P, Arveiler D, Amouyel P, Ferrières J, Ruidavets JB, et al. Is hospital care involved in inequalities in coronary heart disease mortality? J Epidemiol Community Health. 1998;52:665-71.

45. Arber S, McKinlay J, Adams A, Marceau L, Link C, O’Donnell A. Patient characteristics and inequalities in doctor's diagnostic and management strategies relating to CHD: a video-simulation experiment. Soc Sci Med. 2006;62:103-15. 
46. Schieber AC, Kelly-Irving M, Rolland C, Afrite A, Cases C, Dourgnon P, et al. Do doctors and patients remember the same elements of the cardiovascular risk-factors' management after the consultation? The INTERMEDE study. Br J Gen Pract. 2011;61:178-83.

47. Martin E, Russell D, Goodwin S, Chapman R, North M, Sheridan P. Why patients consult and what happen when they do. BMJ. 1991;303:289-92.

48. Taira DA, Safran DG, Seto TB, Rogers WH, Tarlov AR. The relationship between patient income and physician discussion of health risk factors. JAMA. 1997;278:1412-7.

49. Arber S, McKinlay J, Adams A, Marceau L, Link C, O’Donnell A. Influence of patient characteristics on doctors' questioning and lifestyle advice for coronary heart disease: a UK/US video experiment. Brit J Gen Pract. 2004;54:673-8.

50. Lang T, Kelly-Irving M, Delpierre C. Inégalités sociales de santé : du modèle épidémiologique à l'intervention. Enchaînements et accumulations au cours de la vie in (English : Inequalities in health: from the epidemologic model towards intervention Pathways and accumulations along the lifecourse.) Rev Epidemiol Santé Publique. 2009;57:429-35

51. Korkeila J, Vahtera J, Korkeila K, Kivimäki M, Sumanen M, Koskenvuo K, et al. Childhood adversities as predictors of incident coronary heart disease and cerebrovascular disease. Heart. 2010;96:298-303.

52. Forsdahl A. Are poor living conditions in childhood and adolescence an important risk factor for arteriosclerotic disease? Brit J Prev Soc Med. 1977;31:91-5.

53. Barker DJP, Osmond C. Infant mortality, childhood nutrition, and ischaemic heart disease in England and Wales. Lancet. 1986;1(8489):1077-81.

54. Barker DJP. Mothers, babies and health in later life. Edinburgh: Churchill Livingstone; 1998.

55. Hardy R, Kuh D, Langenberg C. Wadsworth MEJ. Birthweight, childhood social class, and change in adult blood pressure in the 1946 British birth cohort. Lancet. 2003;362:1178-83.

56. Roberts CB, Couper DJ, Chang PP, James SA, Rosamond WD, Heiss G. Influence of life-course socioeconomic position on incident heart failure in blacks and whites: the Atherosclerosis Risk in Communities Study. Am J Epidemiol. 2010;172(6):717-27.

57. Roseboom TJ, Van der Meulen JHP, Osmond C. Barker DJP. Coronary heart disease after prenatal exposure to the Dutch famine: 1944-1945. Heart. 2000;84:595-8.

58. Wamala SP, Lynch J, Kaplan GA. Women's exposure to early and later life socioeconomic disadvantage and coronary heart disease risk: the Stockholm female coronary risk study. Int J Epidemiol. 2001;30:275-84.

59. Shonkoff JP, Boyce WT, McEwen BS. Neuroscience, molecular biology, and the childhood roots of health disparities: building a new framework for health promotion and disease prevention. JAMA. 2009;301:2252-9. 
60. Dong M, Giles WH, Felitti VJ, Dube SR, Williams JE, Chapman DP, et al. Insights into causal pathways for ischemic heart disease: adverse childhood experiences study. Circulation. 2004;110:1761-6.

61. Thomas C, Hypponen E, Power C. Obesity and type 2 diabetes risk in midadult life: The role of childhood adversity. Pediatrics. 2008;121:E1240-9.

62. Felitti VJ, Anda RF, Nordenberg D, Williamson DF, Spitz AM, Edwards V, et al. Relationship of childhood abuse and household dysfunction to many of the leading causes of death in adults. The Adverse Childhood Experiences (ACE) Study. Am J Prev Med. 1998;14:245-58.

63. Whitehead M, Dahlgren G. Concepts and principles for tackling social inequities in health. Copenhagen: WHO Europe; 2006.

64. Rose G. The Strategy of Preventive Medicine. Oxford: Oxford University Press; 1992.

65. Leal C, Chaix B. The influence of geographic life environments on cardiometabolic risk factors: a systematic review, a methodological assessment and a research agenda. Obes Rev. 2011;12:217-30.

66. Chaix B, Ducimetière P, Lang T, Haas B, Montaye M, Ruidavets JB, et al. Residential environment and blood pressure in the PRIME Study: is the association mediated by body mass index and waist circumference? J Hypertension. 2008;26:1078-84.

67. Chaix B, Kestens Y, Bean K, Leal C, Karusisi N, Meghiref K, et al. Cohort Profile: Residential and non-residential environments, individual activity spaces and cardiovascular risk factors and diseases--The RECORD Cohort Study. Int J Epidemiol. 2011 Jul 7. [Epub ahead of print]

68. Timio M, Verdecchia P, Venanzi S, Gentili S, Ronconi M, Francucci B, et al. Age and blood pressure changes. A 20 year follow up study in nuns in a secluded order. Hypertension. 1988;12:457-61.

69. Koenen KC, Aiello AE, Bakshis E, Amstadter AB, Ruggiero KJ, Acierno R, et al. Modification of the association between serotonin transporter genotype and risk of posttraumatic stress disorder in adults by county-level social environment. Am J Epidemiol. 2009;169:704-11.

70. Frohlich KL, Potvin L. Transcending the known in public health practice: the inequality paradox: the population approach and vulnerable populations. Am J Public Health. 2008;98:216-21. 